\title{
Stage of Labor
}

National Cancer Institute

\section{Source}

National Cancer Institute. Stage of Labor. NCI Thesaurus. Code C92723.

The various distinct periods of the labor and childbirth process. It involves uterine contractions and cervical dilation to expel the fetus and for the baby to be born. 